\title{
Lactobacillus johnsonii CJLJ103 Attenuates Scopolamine-Induced Memory Impairment in Mice by Increasing BDNF Expression and Inhibiting NF- $\kappa$ B Activation
}

\author{
Hae-Ji Lee ${ }^{1,2}$, Su-Min Lim ${ }^{2}$, and Dong-Hyun Kim ${ }^{1,2 *}$ \\ ${ }^{1}$ Neutrobiota Research Center and ${ }^{2}$ Department of Life and Nanopharmaceutical Sciences, College of Pharmacy, Kyung Hee University, Seoul \\ 02447, Republic of Korea
}

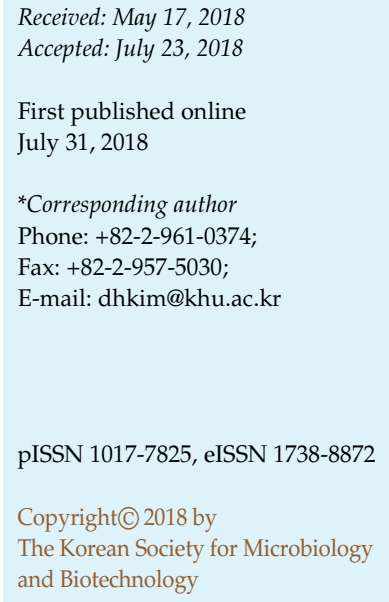

In the present study, we examined whether Lactobacillus johnsonii CJLJ103 (LJ) could alleviate cholinergic memory impairment in mice. Oral administration of LJ alleviated scopolamineinduced memory impairment in passive avoidance and Y-maze tasks. Furthermore, LJ treatment increased scopolamine-suppressed BDNF expression and CREB phosphorylation in the hippocampi of the brain, as well as suppressed TNF- $\alpha$ expression and NF- $\mathrm{BB}$ activation. LJ also increased BDNF expression in corticosterone-stimulated SH-SY5Y cells and inhibited NF- $\mathrm{B}$ activation in LPS-stimulated microglial BV2 cells. However, LJ did not inhibit acetylcholinesterase activity. These findings suggest that LJ, a member of human gut microbiota, may mitigate cholinergic memory impairment by increasing BDNF expression and inhibiting NF-kB activation.

Keywords: Lactobacillus johnsonii, memory impairment, BDNF, NF-кB
Alzheimer's disease (AD) is a neurodegenerative disorder of the central nervous system associated with progressive cognitive failure such as memory loss and language disorders [1]. The AD pathogenesis is characterized by neurotransmitter disturbances and neurofibrillary tangles, which are caused by the deposition of $\beta$-amyloid proteins and abnormal tau proteins, resulting in the impairment of hippocampal and cortical cholinergic cognitive function and immune response [1, 2]. Scopolamine impaired cognitive function, suppressed brain-derived neurotrophic factor (BDNF) expression, and induced TNF- $\alpha$ expression and NF- $\kappa B$ activation $[3,4]$. BDNF stimulates memory formation and plasticity and accelerates long-term potentiation [5]. Scopolamine-induced cholinergic memory impairment is protected by acetylcholinesterase (AChE) inhibitors, such as donepezil, and cholinergic agonists, such as carbachol $[6,7]$. Therefore, increasing BDNF in the brain can be useful to alleviate memory impairment.

The most used probiotics include lactobacilli and bifidobacteria, which are found in fermented foods and human/animal microbiota [8]. Of these, lactobacilli regulate the host's immunity [9] and mitigate memory impairment and metabolic syndrome [10,11]. For example, Lactobacillus plantarum C29 ameliorated aging-dependent, scopolamine-, and 2,4,6-trinitrobenzene sulfonic acid-induced memory impairment in vivo [10, 12, 13]. Lactobacillus johnsonii CJLJ103 (LJ), a member of human fecal microbiota, inhibited LPSinduced memory impairment by inhibiting nuclear factor (NF)-кB activation [14]. However, the effect of CJLJ103 against scopolamine-induced cholinergic memory impairment has not been studied.

Therefore, in the present study, we examined the memory impairment-ameliorating effect of LJ in mice with scopolamine-impaired cognitive function.

LJ was cultured in MRS broth (1 L), centrifuged at 10,000 $\mathrm{g}$ for $20 \mathrm{~min}$, and washed with saline according to the method of Lim et al. [14]. Collected cells were suspended in PBS (for in vitro study) or $1 \%$ glucose (for in vivo study).

Male ICR mice (body weight, 20-23 g; age, 6 weeks) were purchased from Samtaco Animal Inc. (Korea), provided with water and food ad libitum, and maintained in a ventilated room (temperature, $22^{\circ} \mathrm{C} \pm 1{ }^{\circ} \mathrm{C}$; humidity, $50 \% \pm 10 \%$; 
light, 07:00-19:00) for one week before the experiment. All experiments were performed in accordance with the Kyung Hee University Guidelines for University Laboratory Animals Care and Use and were approved by the Committee for the Care and Use of Laboratory Animals in Kyung Hee University (KHUASP(SE)-16-114).

Mice with memory impairment were prepared by the intraperitoneal injection of scopolamine. Scopolamine $(0.9 \mathrm{mg} / \mathrm{kg})$ was intraperitoneally injected into mice $1 \mathrm{~h}$ after the final administration of LJ or saline. $\mathrm{LJ}\left(1 \times 10^{9} \mathrm{CFU} /\right.$ mouse $)$ and vehicle were gavaged once a day for 5 days before the treatment with scopolamine. The final gavage was performed $1 \mathrm{~h}$ before the retention trial. Each group consisted of six mice. Passive avoidance and Y-maze tasks were performed according to the method of Jung et al. [12].

SH-SY5Y cells and BV-2 were cultured at $37^{\circ} \mathrm{C}$ in a $5 \%$ $\mathrm{CO}_{2}-95 \%$ air atmosphere in DMEM containing $1 \%$ antibioticantimycotic and 5\% fetal bovine serum [15]. For the analysis of NF- $\kappa$ B activation, BV-2 cells were treated with LPS (100 ng/ml) in the absence or presence of LJ for $90 \mathrm{~min}$. For the analysis of BDNF expression, SH-SY5Y cells were treated with corticosterone $(300 \mu \mathrm{M})$ in the presence or absence of LJ for $24 \mathrm{~h}$.

Immunoblotting and enzyme-linked immunosorbent assay (ELISA) were performed according to the method of Lee et al. [15]. Acetylcholinesterase activity (AChE) was measured according to the method described by Lee et al. [15].

All data are indicated as the mean \pm standard deviation (SD), with statistical significance analyzed using one-way ANOVA followed by a Student-Newman-Keuls test $(p<0.05)$.

We examined the ameliorating effect of LJ against scopolamine-induced memory impairment in mice by oral administration of LJ at a dose of $1 \times 10^{9} \mathrm{CFU} /$ mouse (Figs. $1 \mathrm{~A}$ and 1B). Treatment with scopolamine significantly reduced spontaneous alterations in the Y-maze task; LPS inhibited spontaneous alterations to $61.9 \%$ of normal control mice. However, oral administration of LJ reversed scopolaminesuppressed spontaneous alterations to $77.1 \%$ of normal control mice. Scopolamine treatment significantly decreased the latency time in the passive avoidance task, whereas treatment with LJ increased scopolamine-reduced latency time. During the acquisition trial, no differences in latency
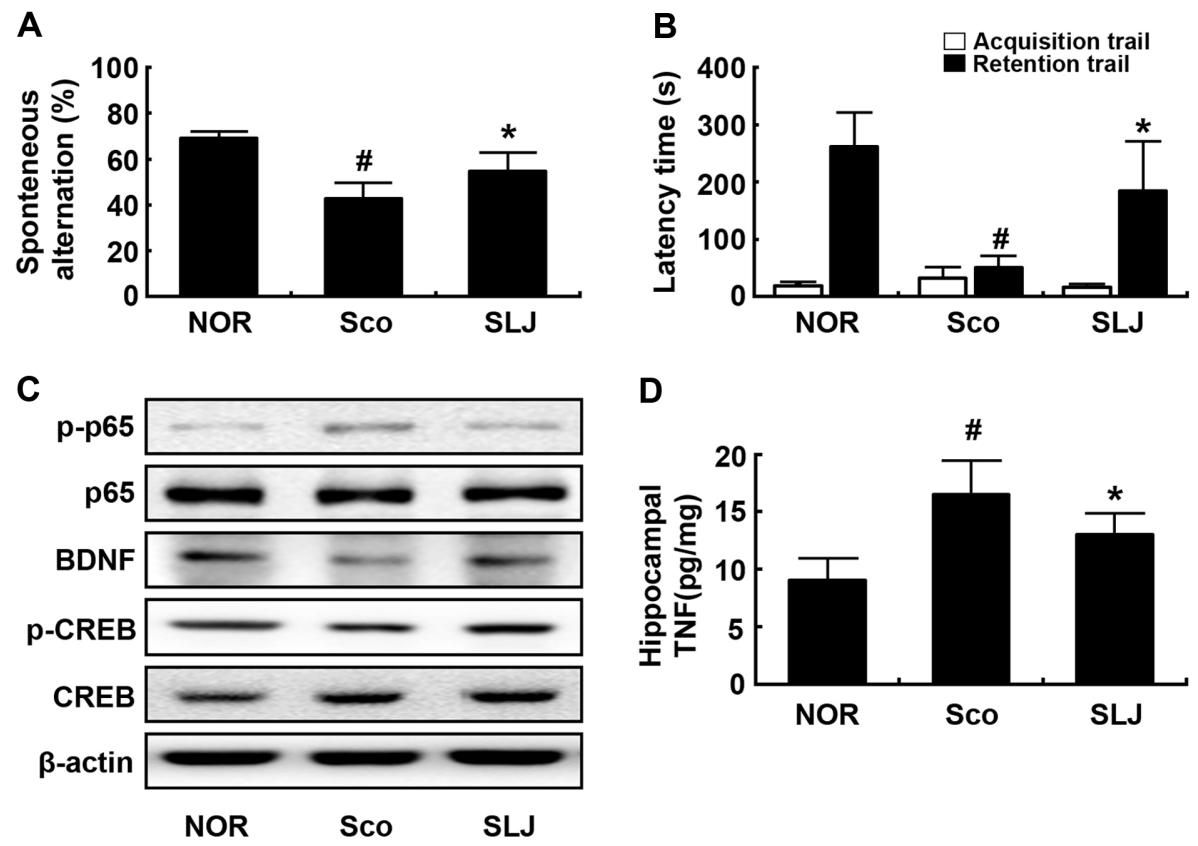

Fig. 1. Effect of Lactobacillus johnsonii CJLC103 (LJ) on scopolamine-induced memory impairment in mice.

(A) Effect in the Y-maze task. (B) Effect in the passive avoidance task. (C) Effect on NF- $\mathrm{KB}$ activation, BDNF expression, and CREB phosphorylation. (D) Effect on hippocampal TNF- $\alpha$ expression. Memory impairment was induced in mice by the intraperitoneal injection of scopolamine $(0.9 \mathrm{mg} / \mathrm{kg})$. LJ $\left(1 \times 10^{9} \mathrm{CFU} /\right.$ mouse) were orally administered once a day for 5 days from $1 \mathrm{~h}$ after the final treatment with LPS. Normal control group (NOR) was treated with saline instead of scopolamine and LJ. BDNF, CREB, p-CREB, and $\beta$-actin were measured by immunoblotting. TNF- $\alpha$ was measured by ELISA. All values are expressed as mean \pm SD $(n=6) .{ }^{*} p<0.05$ vs. normal control group. ${ }^{*} p<0.05$ vs. scopolamine-treated group. 


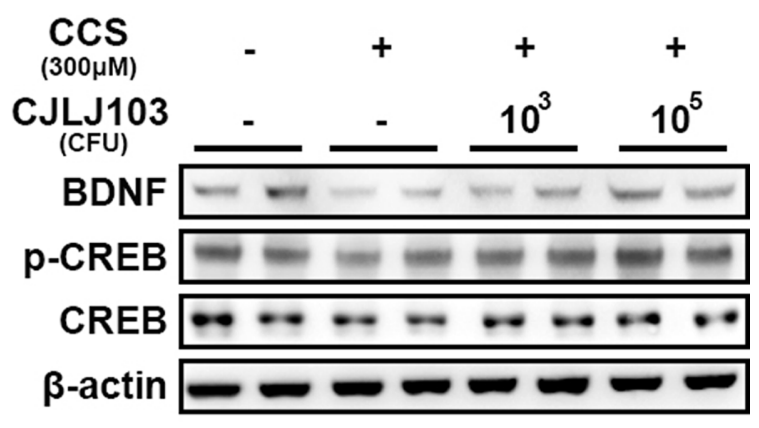

Fig. 2. Effect of Lactobacillus johnsonii CJLC103 on the BDNF expression and CREB phosphorylation in corticosterone (CCS)-stimulated SH-SY5Y cells.

Cells $\left(0.5 \times 10^{6}\right)$ were incubated with corticosterone $(300 \mu \mathrm{M})$ in the absence or presence of $\mathrm{LJ}\left(1 \times 10^{3}\right.$ or $\left.1 \times 10^{5} \mathrm{CFU} / \mathrm{ml}\right)$ for $24 \mathrm{~h}$. Proteins were measured by immunoblotting.

were observed among the test groups. LJ also increased scopolamine-suppressed BDNF expression and CREB phosphorylation and suppressed scopolamine-induced NF- $\kappa$ B activation and TNF- $\alpha$ expression in the hippocampus (Figs. 1C and 1D).

To understand the ameliorating mechanism of LJ against scopolamine-induced impairment, we investigated the inhibitory effect of LJ against AChE activity of electric eel type VI-S and mouse brain homogenate in vitro. LJ did not inhibit the AChE activity (data not shown). Next, we investigated the effect of LJ on BDNF expression and phosphorylation of cAMP response element-binding protein (CREB) in corticosterone-stimulated SH-SY5Y cells (Fig. 2). LJ potently increased corticosterone-suppressed BDNF expression and CREB phosphorylation. Furthermore, LJ inhibited LPS-stimulated NF- $\mathrm{BB}$ activation in the microglial BV2 cells (Fig. 3).

A decrease in the cholinergic function of the brain decreases cognitive function $[2,3]$. Scopolamine, an anticholinergic drug, causes memory impairment in healthy humans. Tariot et al. reported that scopolamine impaired cognitive function, like aging [16]. This is consistent with a previously reported hypothesis that the function of cholinergic neurons decreases with increasing age and dementia [2]. In the present study, we found that scopolamine induced NF- $\mathrm{B}$ activation and TNF- $\alpha$ expression in mice, as was previously reported [5-7]. LJ significantly prevented scopolamineinduced memory impairment in mice in the passive avoidance and Y-maze tasks. However, LJ did not inhibit AChE activity in vitro and in vivo. These results suggest that the amelioration of LJ against memory impairment is not dependent on AChE inhibition. However, LJ induced

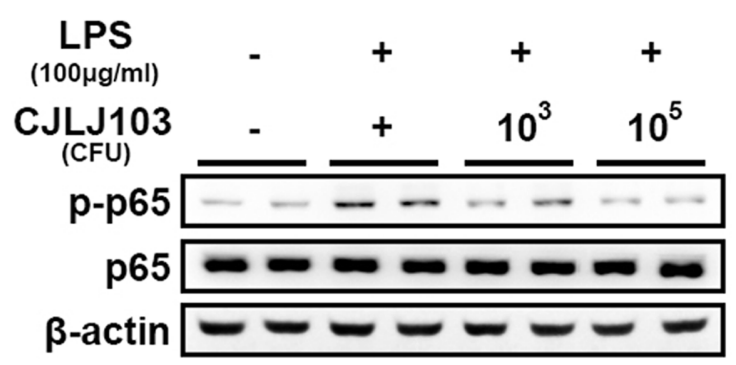

Fig. 3. Effect of Lactobacillus johnsonii CJLC103 on TLR4-linked NF- $\kappa \mathrm{B}$ activation in LPS-stimulated BV-2 cells.

Cells $\left(0.5 \times 10^{6}\right)$ were incubated with LPS in the absence or presence of $\mathrm{LJ}\left(1 \times 10^{3}\right.$ or $\left.1 \times 10^{5} \mathrm{CFU} / \mathrm{ml}\right)$ for $90 \mathrm{~min}$. Proteins were measured by immunoblotting.

BDNF expression and inhibited NF- $\kappa B$ activation and TNF- $\alpha$ expression in scopolamine-treated mice. Additionally, Lim et al. reported that LJ induced BDNF expression and suppressed NF- $\kappa \mathrm{B}$ activation in mice with LPS-induced memory impairment [14]. Moreover, in the present study, we observed that LJ inhibited LPS-induced NF- $\kappa B$ activation in mouse microglial BV-2 cells and increased corticosteronesuppressed BDNF expression in neuronal SH-SY5Y cells. BDNF influences neuronal synaptic plasticity [17], enhancing glutamatergic synaptic transmission $[17,18]$, and facilitating hippocampal LTP [18]. Notably, the expression of BDNF in the entorhinal cortex and hippocampus is lower in patients with $\mathrm{AD}$ than in healthy males [19]. CREB regulates the expression of BDNF and many neuropeptides [5, 20]. These results suggest that LJ may alleviate memory impairment by increasing BDNF expression.

Recent studies have highlighted the crucial role of gut microbiota in the bidirectional gut-brain axis [21]. The colonization of gut microbiota in germ-free mice significantly affects memory-related behaviors and BDNF expression in the brain, attributed to the altered expression of genes involved in second messenger pathways and synaptic longterm potentiation in the brain [21, 22]. The gut microbiota of healthy humans and animals produce toxic substances such as LPS [14, 23]. LPS activates the biosynthesis of inflammation mediators such as TNF- $\alpha$ through the NF- $\kappa B$ signaling pathway, resulting in colitis and learning and memory impairment [14, 22]. Lim et al. reported that LJ suppresses the LPS production of gut microbiota, as well as LPS-stimulated inflammatory responses [14]. Jung et al. reported that scopolamine impaired cognitive function by inducing TNF- $\alpha$ expression [4]. We also found that scopolamine induced TNF- $\alpha$ levels in the brain, as well as $\mathrm{NF}-\kappa \mathrm{B}$ activation in the hippocampi. These results indicate 
that scopolamine can impair cognitive function by inducing NF-kB activation and that inhibiting the NF- $\mathrm{kB}$ signaling pathway in the brain may be beneficial for AD therapy.

On the basis of these findings, we suggest that LJ attenuates cholinergic memory impairment by increasing BDNF expression and inhibiting NF- $\mathrm{kB}$ activation.

\section{Acknowledgments}

This research was supported by the Medical Research Program through the National Research Foundation of Korea (NRF) funded by the Ministry of Science and ICT (NRF-2017R1A5A2014768).

\section{Conflict of Interest}

The authors have no financial conflicts of interest to declare.

\section{References}

1. Britton GB, Rao KS. 2011. Cognitive aging and early diagnosis challenges in Alzheimer's disease, J. Alzheimers Dis. 24 (Suppl 2): 153-159.

2. Araujo JA, Studzinski CM, Milgram NW. 2005. Further evidence for the cholinergic hypothesis of aging and dementia from the canine model of aging. Prog. Neuropsychopharmacol. Biol. Psychiatry 29: 411-422.

3. Jung K, Lee B, Han SJ, Ryu JH, Kim DH. 2009. Mangiferin ameliorates scopolamine-induced learning deficits in mice. Biol. Pharm. Bull. 32: 242-246.

4. Jang YJ, Kim J, Shim J, Kim CY, Jang JH, Lee KW, Lee HJ. 2013. Decaffeinated coffee prevents scopolamine-induced memory impairment in rats. Behav. Brain Res. 245: 113-119.

5. Lu B, Nagappan G, Lu Y. 2014. BDNF and synaptic plasticity, cognitive function, and dysfunction. Handb. Exp. Pharmacol. 220: 223-250.

6. Owen RT. 2016. Memantine and donepezil: a fixed drug combination for the treatment of moderate to severe Alzheimer's dementia. Drugs Today (Barc) 52: 239-248.

7. Gongadze N, Antelava N, Kezeli T, Okudjava M, Pachkoria K. 2008. The mechanisms of neurodegenerative processes and current pharmacotherapy of Alzheimer's disease. Georgian Med. News 155: 44-48.

8. Reid G. 2016. Probiotics: definition, scope and mechanisms of action. Best Pract. Res. Clin. Gastroenterol. 30: 17-25.

9. Kang HJ, Im SH. 2015. Probiotics as an immune modulator. J. Nutr. Sci. Vitaminol. 61 (Suppl): S103-5

10. Jung IH, Jung MA, Kim EJ, Han MJ, Kim DH. 2012.
Lactobacillus pentosus var. plantarum C29 protects scopolamineinduced memory deficit in mice. J. Appl. Microbiol. 113: 1498-1506.

11. He M, Shi B. 2017. Gut microbiota as a potential target of metabolic syndrome: the role of probiotics and prebiotics. Cell Biosci. 7: 54

12. Lee HJ, Jeong JJ, Han MJ, Kim DH. 2018. Lactobacillus plantarum C29 alleviates TNBS-induced memory impairment in mice. J. Microbiol. Biotechnol. 2018.

13. Jeong JJ, Woo JY, Kim KA, Han MJ, Kim DH. 2015. Lactobacillus pentosus var. plantarum C29 ameliorates agedependent memory impairment in Fischer 344 rats. Lett. Appl. Microbiol. 60: 307-314.

14. Lim SM, Jang HM, Jeong JJ, Han MJ, Kim DH. 2017. Lactobacillus johnsonii CJLJ103 attenuates colitis and memory impairment in mice by inhibiting gut microbiota lipopolysaccharide production and NF- $\mathrm{\kappa B}$ activation. J. Funct. Foods 34: 359-368.

15. Lee HJ, Lim SM, Ko DB, Jeong J, Hwang YH, Kim DH. 2017. Soyasapogenol B and genistein attenuate lipopolysaccharideinduced memory impairment in mice by the modulation of NF-кB-Mediated BDNF expression. J. Agric. Food Chem. 65: 6877-6885.

16. Tariot PN, Patel SV, Cox C, Henderson RE. 1996. Agerelated decline in central cholinergic function demonstrated with scopolamine. Psychopharmacology 125: 50-56.

17. Kafitz KW, Rose CR, Thoenen H, Konnerth A. 1999. Neurotrophin-evoked rapid excitation through TrkB receptors Nature 401: 918-921.

18. Figurov A, Pozzo-Miller LD, Olafsson P, Wang T, Lu B. 1996. Regulation of synaptic responses to high-frequency stimulation and LTP by neurotrophins in the hippocampus Nature 381: 706-709.

19. Song JH, Yu JT, Tan L. 2015. Brain-derived neurotrophic gactor in Alzheimer's disease: risk, mechanisms, and therapy Mol. Neurobiol. 52: 1477-1493

20. Shi Z, Chen L, Li S, Chen S, Sun X, Sun L, et al. 2013. Chronic scopolamine-injection-induced cognitive deficit on reward-directed instrumental learning in rats is associated with CREB signaling activity in the cerebral cortex and dorsal hippocampus. Psychopharmacology (Berl) 230: 245-260.

21. Grenham S, Clarke G, Cryan JF, Dinan TG. 2011. Brain-gutmicrobe communication in health and disease. Front. Physiol. 2: 94.

22. Bercik P, Denou E, Collins J, Jackson W, Lu J, Jury J, et al. 2011. The intestinal microbiota affect central levels of brainderived neurotropic factor and behavior in mice. Gastroenterology 141: 599-609.

23. Xie G, Wang X, Liu P, Wei R, Chen W, Rajani C, et al. 2016. Distinctly altered gut microbiota in the progression of liver disease. Oncotarget 7: 19355-19366. 